It is at present too early to give general advice about the attitude which the court will adopt to these proceedings. So far, the Medical Defence Union has instructed its solicitors to oppose such an application on one occasion and the application was dismissed with costs. There are a number of other applications threatened.

The purpose of this letter is to alert practitioners to a procedure which is adopted by some solicitors of writing to doctors drawing their attention to these new Rules and indicating that, if they do not voluntarily disclose their records, powers are available whereby the court can compel them to do so. The Union's solicitors consider that it will be a year or two before the general attitude of the court towards these applications will be crystallized, and it should not be assumed that because a solicitor makes an application it will necessarily be successful. Even if it is successful there are almost inevitably in a patient's medical records entries and reports which have no relevance to the litigation and which should not be disclosed.

The Medical Defence Union accordingly strongly advises all practitioners who receive an approach of this kind from solicitors to consult their defence organization forthwith in order that appropriate guidance may be given. Each case will have to be considered on its own merits at present, and no useful purpose would be served by endeavouring to lay down general guidelines until the Rule has been in operation for some time. -I am, etc.,

London W.C.1

Phillp H. Addison

**An article by our Legal Correspondent appears at p. 577.-ED., B.M.f.

\section{Cardiac Arrhythmias during Laparoscopy}

SIR,-It might be argued that the high incidence of cardiac arrhythmia which Drs D. B. Scott and D. G. Julian found during anaesthesia for laparoscopy in which carbon dioxide was used for peritoneal insufflation (12 February, p. 411) was due to an entirely inappropriate type of anaesthetic rather than to the use of carbon dioxide in the peritoneum.

A technique of anaesthesia based on the use of small doses of gallamine and halothane $(2 \%)$ with the patient breathing spontaneously might be expected to lead to an appreciable rise in the blood carbon dioxide tension in many situations. This is especially so in laparoscopy in which carbon dioxide is used for peritoneal insufflation. Here carbon dioxide will be absorbed from the peritoneum, and the respiratory response to the extra carbon dioxide will be imoaired, not only because of the use of gallamine and halothane. but also because the diaphragm will be working at a mechanical disadvantage owing to the presence of gas in the peritoneum and, usually, to the use of a steep head-down tilt.

It would be difficult to imagine a better indication for the use of an anaesthetic technique based on the one of a moderate degree of passive pulmonary hyperventilation. If this is employed there seems no reason to abandon the use of carbon dioxide for peritoneal insufflation.-I am, etc.,

Department of Anaesthesia,
University of Liverpool

J. E. UTTING
SIR,-It is interesting that Drs. D. B. Scott and D. G. Julian (12 February, p. 411) advocate that the problem of carbon dioxide absorption with the consequent possibility of eardiac irregularities (albeit without haemodynamic disadvantage) be remedied by the substitution of nitrous oxide as the insufflating medium, even though the former, being less soluble, is theoretically less suitable.

It would appear that there is a simpler and more radical way. Accumulation of carbon dioxide resultant upon their use of a mask, with respiratory movement damped down by gallamine and halothane and mechanically hindered by abdominal distension, is readily preventable by the use of full relaxation with intermittent positive pressure respiration via an endotracheal tube. In this way a tidal volume adequate to deal with carbon dioxide absorption from the peritoneal cavity can be maintained. This will in addition avoid any danger from regurgitation and, in the presence of adequate premedication, obviate the need for halothane with its disadvantage in the immediate postpartum patient who requires sterilization.

I wonder if this is not a safer and more physiologically accurate method. It has certainly given no problems so far.-I am, etc.,

Isle of Thanet District Hospital,

Travers SAYER

Margate, Kent

\section{Doctors and Overpopulation}

SIR,-I write as invited by Lord Brock (12 February, p. 440). I am one of the signatories of the letter "Doctors and Overpopulation" (8 January, p. 108), and also have some experience of both male and female sterilization.

He agrees that "as responsible, thinking citizens there is no doubt that we have, or should have, great concern" about the problems of overpopulation. Failing to see this as "a medical concern," he then states that in our letter we are speaking as social reformers, not as doctors. At one point in his letter he makes a further statement, the logic of which escapes me, that one of our objectives may be to abandon the Hippocratic code-though later conceding that a change "to include a social code," rather than abandonment, is involved.

Personally, and I am sure that in this I am speaking for the others who signed on 8 January, I consider we were writing not so much as social reformers as about no less a question than survival. Before dismissing this as "doomsday talk," it should be realized that population projections for a given year in the future do not mean that the figure will necessarily be reached-they merely refer to the expected numbers if current trends were to continue. We live on a finite island, the number of whose inhabitants is increasing at about 700-800 persons a day, situated on a finite "spaceship earth," which is required at present to accommodate 200,000 new passengers da:ly. Yet this country imports half its food, being able to do so at present because it has money; inevitably, if present worldwide and national trends continue, a time must come when the rest of the world has insufficient food to sell. We may then find our money rather indigestible.

In the face of this degree of urgency, though vasectomy (about which Lord Brock seems chiefly concerned) is no panacea, it must be made available on voluntary nonstrictly-medical grounds, as widely as possible, and preferably without payment of any fee by the patient. If this requires a change in the Hippocratic code to include a social code, then why not? If we can support this kind of action as "responsible, thinking citizens," then why not as doctors? And fears about the future inclusion of a communist code, or of any element of compulsion, are groundless if sufficient action is taken on a voluntary basis now.

I think that we did give this aspect "real cold thought" before signing the letter. Indeed, Sir, perhaps the really "cold thought" is the one about the stringent measures which may become unavoidable if continuing population growth is not halted. Perhaps some warmth and reassurance can be derived from the fact that over 800 doctors have now written in support of our views.I am, etc.,

JOHN GUILlebaud

Oxford Chairman, Population Committee,

SIR,-Drs. Shirley and Philip Nicholas (5 February, p. 377) complain "What a struggle it has been to get contraceptive instruction to the midwives...."

The Central Midwives Board has included the subject of family planning in the training of pupil midwives and has encouraged lectures on family planning in all approved refresher courses since 1968.

Midwives are well placed to advise their patients on contraception and sterilization but these techniques are essentially the province of a doctor. The Board does not include the practical application of contraceptive methods in its syllabus, but encourages midwives to attend Family Planning Association courses.-I am, etc.,

HUMPHREY ARTHURE London S.W.7

Chairman, Central Midwives Board

\section{Malnutrition and Body Temperature}

SIR,-Dr. O. G. Brooke's observation (5 February, p. 331) that the temperatures of hypothermic children in a thermoneutral environment are dropping at the rate of over $3^{\circ} \mathrm{C}$ in 12 hours emphasizes the very acute nature of the hypothermic emergency. These children are dying before one's eyes, and the fact that this process can be so easily reversed with frequent feeds is a very notable finding. Those of us who have tried to rewarm these children by physical means know how difficult this can be and how often we failed.

The effects of hypothermia, usually known as cold injury, persist long after the temperature has returned to normal, and we would be very interested to see any observations that Dr. Brooke has in this regard. We were of the opinion in 1963 , and we remain of the opinion, that the clinical syndrome of kwashiorkor is in fact the result of hypothermia in a malnourished child. It is the form taken by cold injury superimposed on a malnourished state.

Kwashiorkor can be of very acute onset. We have ourselves seen two cases both of which developed the full-blown picture overnight in a hospital ward. Many of the child- 
ren's mothers when questioned will give a history of acute overnight onset. Dr. Brooke's observation of the rapid drop in temperature of the sleeping malnourished child no doubt provides the explanation for these cases.-We are, etc.,

JAMES LAWLESS

Skeeby, Richmond,

Yorks

MARGARET M. LAWLESS

\section{The Pill and the Pituitary}

SIR,-Your leading article of three months ago (27 November, p. 510) states that "none of the patients had an obvious endocrinological cause ... of the [post-pill] amenorrhoea, such as pituitary tumour. ..."

A 30-year-old nullipara with a pre-pill regular menstrual habit of 5/30 was referred because of 21 months' amenorrhoea since discontinuing oral contraception after four years of use. Her general condition was good and she had no other symptoms but milk was freely expressed from her breasts. The vulva and vagina were not atrophic but the uterus was small. $X$-ray of the pituitary fossa was reported as negative. Two courses of clomiphene were ineffective.

Inquisitive as to whether any anterior pituitary depressant action of the pill was confined to gonadotrophin production, I referred the patient to the Liverpool Endocrine Clinic. Dr. J. C. Davis found no evidence of other deficiency but tomographs indicated a small pituitary tumour. Hypophysectomy was performed by Mr. C. B. Sedzimir at Walton Hospital, Liverpool. Subsequently the patient had an episode of C.S.F. rhinorrhoea and meningitis but made a good recovery after which there was evidence of poor adrenocortical function, hypothyroidism, mild diabetes insipidus, and absent gonadotrophin production. She moved to Hull from where, 18 months after operation, Mr. A. N. Guthkelch's department reported that she was well on cortisone and thyroxine. Her galactorrhoea had gradually disappeared but her amenorrhoea of course persists. Fortunately she is not concerned about fertility.-I am, etc.,

\section{Chester}

S. BENDER

\section{Enzyme Induction and Folate Deficiency}

SIR,-The role of the liver in normal and abnormal folate metabolism has received insufficient attention. As the major anticonvulsant drugs, especially phenytoin and phenobarbitone, are powerful inducers of liver enzymes, and are ingested in high dosage for many years, it seems likely that they will disturb the metabolism of many substances, both exogenous and endogenous. It was for this reason that Dr. A. H. Waters and I suggested to the British Pharmacological Society last year ${ }^{1}$ that enzyme induction may be an aetiological factor in anticonvulsant-induced folate deficiency. We presented evidence on the acute effect of phenytoin on serum folate concentration, showing that a progressive fall occurred in normal subjects taking $1,600 \mathrm{mg}$ of the drug orally over four days. Six days after the subjects stopped taking the drug the serum folate concentration had returned almost to normal. We considered that the time course of this effect could be explained by a druginduced change in liver enzyme activity, although it by no means ruled out other effects, such as impaired absorption of dietary folate. Dr. J. D. Maxwell and others (29 January, p. 297) have now shown an inverse corretation between serum folate concentration and urinary D-glucaric acid excretion. As pointed out previously ${ }^{2}$ in relationship to vitamin $\mathbf{D}$ metabolism a correlation between measures of two druginduced abnormalities is to be expected, for both will show a dose relationship with the drug in question. There remains the possibility that folic acid deficiency is produced by some other dose-related effect than enzyme induction. So, although the observation provides supporting evidence, too great an emphasis should not be placed upon it, especially as the position which urinary Dglucaric acid holds as a measure of liver enzyme induction still requires evaluation. ${ }^{3}$ However, as Dr. Maxwell and others discuss, evidence is accumulating that altered liver enzyme activity is important in the production of osteomalacia in epileptic patients, ${ }^{2}$ and, in addition, it can lead to an increase in the turnover of cortisol, oestrogens, and androgens, ${ }^{4}$ and explains a number of anticonvulsant drug interactions. ${ }^{5}$

In view of the disappointing results of many studies on the aetiology of anticonvulsant-induced folate deficiency liver enzyme induction should be looked upon as the most promising current hypothesis to explain the abnormality, but a great deal more work will be required before the question is resolved.-I am, etc.,

\section{Alan Richens}

\section{Department of Clinical Pharmacology,}

St. Bartholomew's Hospital,

1 Richens, A., and Waters, A. H., British fournal 2 Richens, A., and Rowe, D. J. F., British Medical Fournal, il971, 4, 684.
Aarts, E. M., Lancet, 1971, 1, 859.

4 Kuntzman, R., Annual Review of Pharmacology,

1969, 9, 21. Annual Review of Pharmacology,
5 Hansen, J. M. Siersboek-Nielsen, K., and puetics, 1971, 12, 539.

\section{Haemophilus Epiglottitis}

SIR,-The recent paper about "Haemophilus Epiglottitis" by Dr. M. G. Addy and others (1 January, p. 40) and subsequent letters prompt us briefly to record our experience in the last two months.

Though aware of the condition as a serious clinical entity for many years we do not remember sudden deaths from croup during the last nine years at this hospital, and can recall requiring a tracheostomy to be performed on only three children with "croup" during that time. This winter croup has shown a different pattern, and four children with haemophilus epiglottitis have been admitted to our hospitals.

Only the last patient (aged 5) was correctly diagnosed on arrival. He was in asystole and visualization of the epiglottis was necessary immediately for intubation. Though successfully resuscitated (after an estimated 15 minutes' cardiac arrest) the patient died a few hours later. The first two patients admitted by different doctors were diagnosed as laryngitis but were given hydrocortisone with ampicillin by injection. Both were considered not to have sufficient respiratory obstruction to require interference but were treated with moist atmosphere and sedation. Both deteriorated suddenly after two hours. The first, aged 13 months, developed respiratory arrest and coma. Intubation proved impossible because of the size of the epiglottis but oxygenation was well maintained by Ambubag until tracheostomy. He recovered, but the attendant who attempted intubation as an emergency procedure, without donning a mask, developed haemophilus pneumonia (which did not respond to ampicillin, though the organism was sensitive to this). The second patient, aged four, became unconscious and had cardiac arrest as he was moved from his pillows to prepare for tracheostomy. He did not respond to resuscitation. Intubation through the cords was easily possible post mortem, suggesting that death was from toxaemia rather than anoxia.

Since this tragic death all cases of croup are designated epiglottitis until proved otherwise. They all receive chloramphenicol and hydrocortisone on admission and the consultant is informed. The tracheostomy trolley is laid up beside the cot and all requisites for resuscitation are arranged on a second trolley. No attempt is made to do immediate laryngoscopy.

Despite this, the diagnosis on the third patient, aged 20 months, was not recognized at once, and he showed gradual improvement over the first six or seven hours and then suddenly, without further provocation, developed cardiac arrest. An endotracheal tube was passed and resuscitation was successful but voluntary respiration was associated with intercostal and subcostal recession in part due to airway obstruction and in fart to pneumonia.

In view of the temporary nature of the swelling of the epiglottis a decision was made to leave the tube in situ and not to perform a tracheostomy. However, a further cardiac arrest ensued, and on the way to theatre for tracheostomy the heart stopped again. Tracheostomy was complicated by bilateral pneumothorax, which responded quickly to treatment. The tube could be removed after five days, but the child became febrile and ill again, convulsed, and stopped breathing 12 hours after its removal. The tube was reinserted for the purpose of artificial ventilation over the next 36 hours, after which the fever subsided and a rubella rash developed. There was severe hypotonia and athetosis but no detectable intellectual impairment. Gradual recovery is occurring.

These cases obviously underline the fulminating nature of this condition and the difficulty in diagnosis when the doctor has had no previous experience of it. They also demonstrate a hazard not mentioned in the other communications-that of cross infection to the attendant medical and nursing staff-and suggest endotracheal intubation as a method of maintaining the airway is undesirable if it does not completely relieve the obstruction in a patient likely to develop cardiac arrest. In our opinion a tracheostomy is easier to manage and causes less irritation to the patient. The scars are minimal and a small price to pay for survival.-We are, etc.,

Patricia E. Mortimer M. B. Stanton

Chase Farm Hospital,

F. J. WOODROFFE

\section{Lead Poisoning Scandal}

SIR,-In the Sunday Times (30 January) and also on television (28 January, Dr. R. Murray) it was stated that the Factory Inspectorate doctor involved was also the company doctor. The integrity of the doctor 